\title{
High Density Interconnect Microstrip Patch Antenna for 5G Base Stations with Integrated Filtering Performance
}

\author{
Marco Salucci ${ }^{1}{ }^{(\mathbb{D})}$, Cristian Castlunger ${ }^{1}$, Davide Marcantonio ${ }^{1}$, Giacomo Oliveri ${ }^{1}$ (i), \\ Fabrizio Robol ${ }^{1}$, Pietro Rosatti ${ }^{1}$, Luciano Tosato ${ }^{1}$, Francesco Zardi ${ }^{1}$ and Andrea Massa ${ }^{1,2, *}$ (D) \\ 1 ELEDIA Research Center (ELEDIA@UniTN_University of Trento), Via Sommarive 9, I-38123 Trento, Italy; \\ marco.salucci@unitn.it (M.S.); cristian.castlunger@eledia.org (C.C.); davide.marcantonio@eledia.org (D.M.); \\ giacomo.oliveri@unitn.it (G.O.); fabrizio.robol@unitn.it (F.R.); pietro.rosatti@eledia.org (P.R.); \\ luciano.tosato@eledia.org (L.T.); francesco.zardi@eledia.org (F.Z.) \\ 2 ELEDIA Research Center (ELEDIA@UC3M-Universidad Carlos III de Madrid), Avenida de la Universidad 30, \\ 28911 Leganés, Madrid, Spain \\ * Correspondence: andrea.massa@eledia.org or andrea.massa@unitn.it; Tel.: +39-0461-282057
}

Received: 10 March 2018; Accepted: 24 April 2018; Published: 27 April 2018

check for updates

\begin{abstract}
The elementary radiator of a planar array for next generation millimeter-wave (mm-wave) 5G base stations is described. The antenna is designed for high density interconnect (HDI) manufacturing for yielding a compact, densely-interconnected, and highly-integrable stacked structure. The layout of the single element is determined by directly optimizing key radiation features of the whole planar arrangement according to specific application-driven requirements. In addition, thanks to the exploitation of a spline-shaped modelling of the radiator, suitable performance in terms of impedance matching, realized gain, half-power beamwidth (HPBW), polarization purity, and inter-element isolation are achieved within the 28-GHz pass-band. Moreover, integrated out-of-band filtering capabilities are obtained in selected and wide non-contiguous stop-bands without additional circuitry.
\end{abstract}

Keywords: 5G base station; mm-wave antenna design; high density interconnect (HDI); filtering antenna; spline shape; embedded element analysis

\section{Introduction and Motivation}

The rapid development of fifth-generation (5G) wireless communication systems involves unprecedented challenges to meet new and conflicting requirements including (but not limited to) extremely high data rates and traffic volume/density, low latency, enhanced energy and spectral efficiency, as well as reduced costs and sizes [1-3]. The use of millimeter-wave (mm-wave) bands in combination with highly directive and reconfigurable phased arrays is considered a key enabler towards the future 5G system requirements [4-6]. As a matter of fact, a reliable high-throughput coverage of multiple users in large urban areas can be yielded with compact new-generation base stations thanks to the small wavelength at $\mathrm{mm}$-frequencies. More specifically, both the research and the technological scouting have been mainly concerned with the $28-\mathrm{GHz}(25.25-29.5 \mathrm{GHz})$ and the $38-\mathrm{GHz}(36.25-40.5 \mathrm{GHz})$ bands, the rain attenuation and oxygen absorption being lower than in the other portions of the spectrum announced by the Federal Communications Commission (FCC) for 5G services [7-9] (i.e., 6-300 GHz). Dealing with mm-waves, one of the most critical and challenging tasks in realizing high-performance $5 \mathrm{G}$ base stations is the design of innovative antennas able to simultaneously comply with several contrasting requirements on (i) size, (ii) impedance matching, (iii) half-power beamwidth (HPBW), (iv) cross-polarization, and (v) isolation [10]. Moreover, a very 
desirable feature is the integration of filtering capabilities directly into the radiating structure without dedicated circuitry $[7,11]$. Indeed, a wide stop-band is typically necessary to suppress harmonics originated by power amplifiers in transmission as well as to reject out-of-band signals that could affect the low noise amplifiers of the receiving chain. However, cascading broadband antennas and filters-as done in classical array designs-here would significantly increase the complexity and the overall size of the radiating system. Moreover, the unavoidable occurrence of insertion losses would reduce the radiation gain [12]. Therefore, alternative solutions, such as those based on the "co-design" approach, have been recently explored [7-13].

As for the increasing demand for compact layouts, high density interconnect (HDI) [13-15] is rapidly emerging as a promising manufacturing technology in the design process of advanced 5G devices since HDI-printed circuit boards (PCBs) support high-density attributes (e.g., laser drilled microvias) and they allow buried routing within multi-layered highly-interconnected structures. This opens the doors to the low cost system miniaturization and integration for mass production [15].

Starting from these considerations, the design of a novel HDI-manufactured mm-wave planar array for $5 \mathrm{G}$ base stations working in the $28-\mathrm{GHz}$ band is proposed here. A spline-based shape modelling [16] is exploited to simply/efficiently describe a wide (also complex-shapes) set of possible geometries of the single radiator without recurring to a huge number of descriptors/degrees-of-freedom (DoFs). Unlike conventional design methods, the synthesis of the single array element is carried out by directly optimizing, with a customized Particle Swarm Optimization (PSO) algorithm [17-24], the radiation performance of the entire array layout to fit all the user-defined requirements in terms of in-band behavior and geometrical constraints, while exhibiting integrated filtering capabilities to yield the desired out-of-band rejection within wide and non-contiguous stop-bands.

The paper is organized as follows. Section 2 lists the user-defined design requirements and it describes the proposed HDI-based elementary radiator. The results of full-wave analyses are presented next (Section 3) to show the performance of the single embedded element as well as to assess its effectiveness in fitting the design objectives when integrated into the final planar array arrangement. Finally, some concluding remarks are drawn (Section 4).

\section{HDI-Based 5G Filtering Antenna Design}

The geometry of the planar array is depicted in Figure 1, while Table 1 summarizes the design requirements considered in the synthesis process imposed by the customer for the specific application.

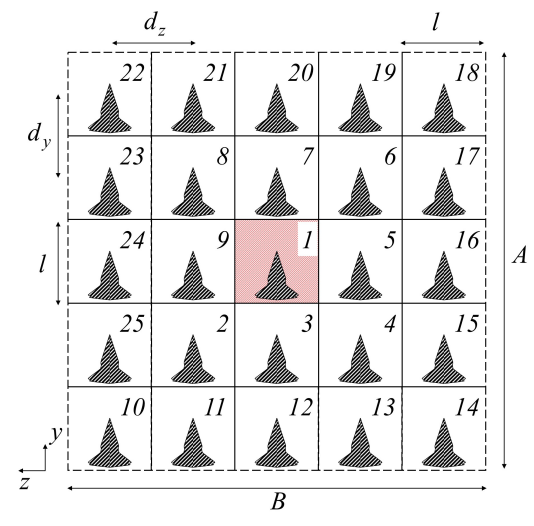

(a)

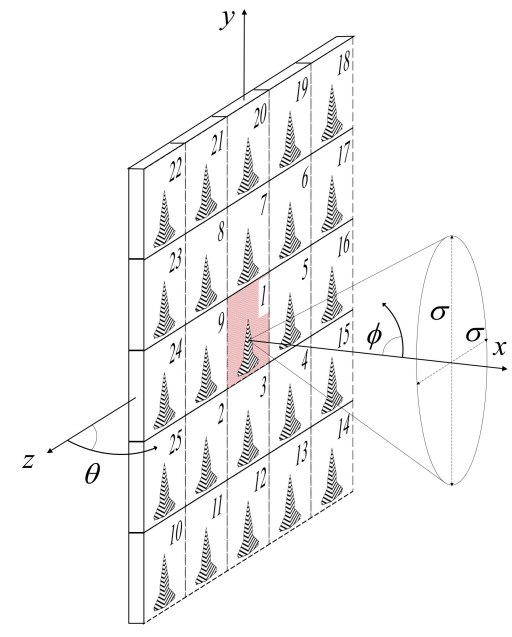

(b)

Figure 1. Front view (a) of the 28-GHz planar array for 5G base stations and (b) reference coordinate system, showing the considered elements numbering for identifying the central embedded element $(n=1)$ and the surrounding radiators $(n=2, \ldots, N=25)$. 
The antenna lies on the $(y, z)$ plane (Figure 1$)$ and it is designed to operate over a portion of the 28-GHz band [9] (defined by the customer) with a low input reflection (i.e., $\left|S_{11}(f)\right| \leq-10 \mathrm{~dB}$ ) along the $f \in\left[f_{\min }^{(p)}, f_{\max }^{(p)}\right]=[27.8,29.0](\mathrm{GHz})$ pass-band (Table 1). Furthermore, out-of-band filtering in wide non-contiguous stop-bands is required without recurring to an additional circuitry. More precisely, $\left|S_{11}(f)\right| \geq-2 \mathrm{~dB}$ is mandatory within the frequency range $f \in\left[f_{\min }^{\left(s_{1}\right)}, f_{\max }^{\left(s_{1}\right)}\right]=[31.0,38.0](\mathrm{GHz})$ (1st priority stop-band-Table 1), while $\left|S_{11}(f)\right| \geq-5 \mathrm{~dB}$ is desirable over the $f \in\left[f_{\min }^{\left(s_{2}\right)}, f_{\max }^{\left(s_{2}\right)}\right]=$ $[50.0,55.0](\mathrm{GHz})$ band (2nd priority stop-band-Table 1). Concerning the overall extension of the aperture on the $(y, z)$ plane, the length and width are limited by mechanical/geometrical constraints to $A \leq 28 \mathrm{~mm}$ and $B \leq 28 \mathrm{~mm}$, respectively (Figure 1 and Table 1). Under such requirements, the array lattice has been chosen so that there are no grating lobes in the whole pass-band and within a scan cone of width $\sigma=120 \mathrm{deg}$ around the broadside (with reference to the coordinate system in Figure $1 \mathrm{~b}$, the direction $\left(\theta_{0}, \phi_{0}\right)=(90,0)(\mathrm{deg})$ is the antenna broadside-Table 1$)$. It turned out a planar arrangement of $N=25$ elements uniformly-spaced by $d_{y}=d_{z}=l=\frac{\lambda_{c}^{(p)}}{2}=5.28 \mathrm{~mm}, \lambda_{c}^{(p)}$ being the free-space wavelength at the central operative frequency $f_{c}^{(p)}\left(f_{c}^{(p)} \triangleq \frac{f_{\min }^{(p)}+f_{\max }^{(p)}}{2}=28.4 \mathrm{GHz}\right)$, whose superficial extension is $A \times B=26.4 \times 26.4 \mathrm{~mm}$.

As for the radiation characteristics, the array must provide a maximum realized gain $G_{\max }(f)=$ $\max _{(\theta, \phi)} G(f, \theta, \phi) \geq 18 \mathrm{~dB}$ with low ripple (i.e., $\zeta \leq 1 \mathrm{~dB}$-Table 1) in the $f \in\left[f_{\text {min }^{\prime}}^{(p)} f_{\text {max }}^{(p)}\right]$ band (the ripple $\zeta$ is defined as the maximum difference between adjacent peaks and valleys in the realized-gain vs. frequency diagram (i.e., $G_{\max }(f)$ ) within the working frequency range). Moreover, a high inter-element isolation is required with scattering coefficients $\left|S_{n 1}\right| \leq-18 \mathrm{~dB}$ (Table 1) between the central embedded radiator (i.e., $n=1$-Figure 1) and its closest neighbors (i.e., $n=2, \ldots, 9$-Figure 1). Furthermore, the in-band azimuthal (i.e., $\phi=0 \mathrm{deg}$ ) and elevation (i.e., $\theta=90 \mathrm{deg}$ ) half-power beam-widths (HPBWs) must be smaller than the threshold value $H P B W_{t h}=25$ deg (i.e., $\left.H P B W\right|_{\phi=0 \operatorname{deg}} \leq H P B W_{t h}(\mathrm{deg})$ and $\left.H P B W\right|_{\theta=90[\mathrm{deg}]} \leq H P B W_{t h}(\mathrm{deg})$ ). Finally, a vertically-polarized (i.e., $y$-oriented) field must be radiated within the angular region $\phi \in[-60,60](\mathrm{deg}) \cup \theta \in[75,105]$ (deg), the axial ratio and the ellipticity angle being $A R(\theta, \phi) \geq$ $20 \mathrm{~dB}$ and $|\chi| \leq 10 \mathrm{deg}$, respectively (the axial ratio being defined as $A R(\theta, \phi)=\frac{\gamma_{1}(\theta, \phi)}{\gamma_{2}(\theta, \phi)}$, while the (broadside) ellipticity angle is equal to $\chi=\arctan \left[\frac{\gamma_{2}\left(\theta_{0}, \phi_{0}\right)}{\gamma_{1}\left(\theta_{0}, \phi_{0}\right)}\right], \gamma_{1}(\theta, \phi)$ and $\gamma_{2}(\theta, \phi)$ being the major and the minor axes of the polarization ellipse in the $(\theta, \phi)$ direction, respectively-Table 1).

In order to fit all these radiation requirements subject to the assigned geometrical constraints (Table 1), the geometry of the elementary radiator shown in Figure 2 has been properly synthesized by considering a two-layer structure and the HDI fabrication [15] as dictated by the customer. Accordingly, off-the-shelf HDI dielectric boards have been adopted. In more detail, the bottom feeding substrate is a ground-backed Laminate R-5785(N) with relative permittivity $\varepsilon_{f}=3.34$, dielectric loss tangent $\tan \delta_{f}=3.0 \times 10^{-3}$, and thickness $d_{f}=0.5 \mathrm{~mm}$, while the top layer is Prepreg R-5680 with $\varepsilon_{1}=3.6$, $\tan \delta_{1}=4.0 \times 10^{-3}$, and $d_{1}=0.132 \mathrm{~mm}$ (Figure 2a). A microstrip line of length $b$ and width $a$ has been etched on top of the feed substrate and it is used to excite the overlying (solid) radiating patch. Concerning the latter, its shape has been modeled with a spline-based technique [16] to increase the set of possible patch shapes without recurring to complex or huge-number of DoF descriptors and allow an effective fitting of all performance requirements (Figure $2 b$ ). To force a geometrical/electric symmetry, only one half of the patch contour has been optimized by setting a set of $K=8$ control points for the spline curve, $p_{k}=\left(y_{k}, z_{k}\right), k=1, \ldots, K$ (Figure $2 \mathrm{~b}$ ), points $p_{2}, \ldots, p_{7}$ being automatically mirrored with respect to the $(x, y)$ symmetry plane (Figure $2 b)$. 


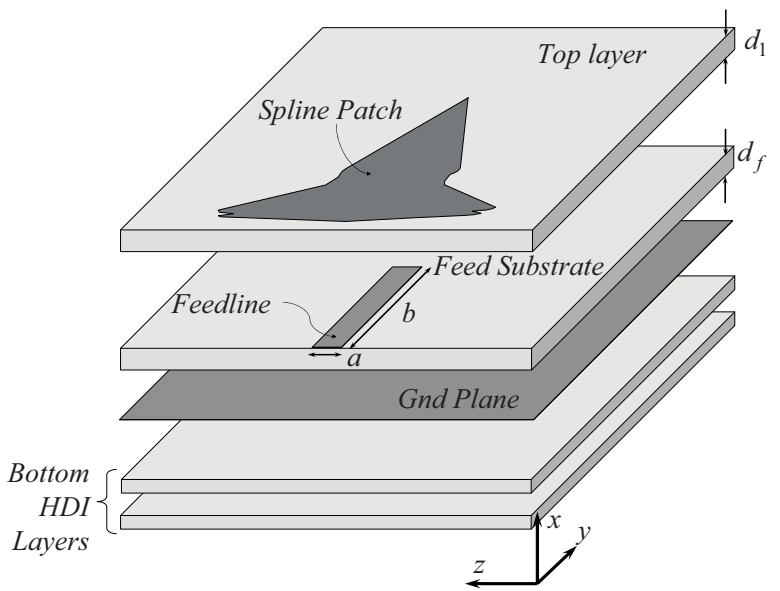

(a)

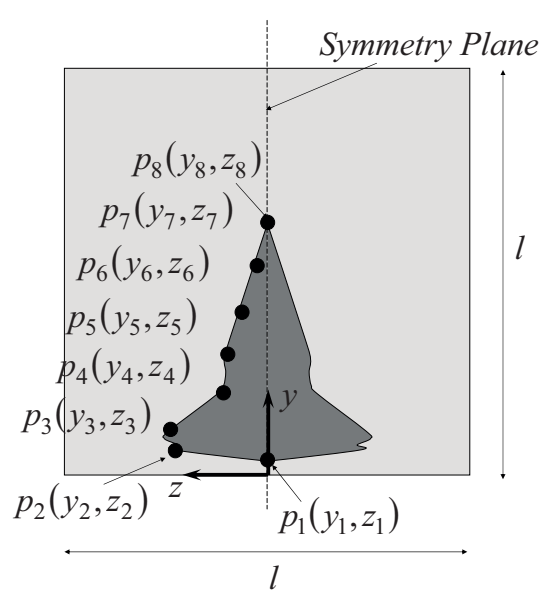

(b)

Figure 2. Geometry of the HDI-based 5G filtering patch radiator: (a) 3D and (b) top views.

Table 1. 5G array design—Performance and geometric/mechanical design requirements.

\begin{tabular}{cc}
\hline Parameter & Requirement \\
\hline Pass-Band & {$\left[f_{\min }^{(p)} f_{\max }^{(p)}\right]=[27.8,29.0](\mathrm{GHz})$} \\
Reflection Coefficient & $\left|S_{11}(f)\right| \leq-10 \mathrm{~dB}, f \in\left[f_{\min ^{\prime}}^{(p)} f_{\max }^{(p)}\right]$ \\
Stop-Bands & 1st Priority: $f \in\left[f_{\min }^{\left(s_{1}\right)}, f_{\max }^{\left(s_{1}\right)}\right]=[31.0,38.0](\mathrm{GHz})$ \\
2nd Priority: $f \in\left[f_{\min }^{\left(s_{2}\right)}, f_{\max }^{\left(s_{2}\right)}\right]=[50.0,55.0](\mathrm{GHz})$ \\
Out-of-Band & 1st Priority: $\left|S_{11}(f)\right| \geq-2 \mathrm{~dB}, f \in\left[f_{\min }^{\left(s_{1}\right)}, f_{\max }^{\left(s_{1}\right)}\right]$ \\
Rejection & 2nd Priority: $\left|S_{11}(f)\right| \geq-5 \mathrm{~dB}, f \in\left[f_{\min }^{\left(s_{2}\right)}, f_{\max }^{\left(s_{2}\right)}\right]$ \\
Array Size & $A \leq 28 \mathrm{~mm}, B \leq 28 \mathrm{~mm}$ \\
Scan Cone & $\sigma=120 \mathrm{deg}$ \\
Realized Gain & $G_{\max } \geq 18 \mathrm{~dB}$ \\
Gain Ripple & $\zeta \leq 1 \mathrm{~dB}$ \\
Isolation & $\left|S_{n 1}(f)\right| \leq-18 \mathrm{~dB}, f \in\left[f_{\min }^{(p)}, f_{\max }^{(p)}\right], n=2, \ldots, 9$ \\
Azimuthal HPBW & $\left.H P B W\right|_{\phi=0}[\mathrm{deg}] \leq 25.0 \mathrm{deg}$ \\
Elevation HPBW & $\left.H P B W\right|_{\theta=90[\mathrm{deg}]} \leq 25.0 \mathrm{deg}$ \\
Polarization & Linear $(\operatorname{Vertical})$ \\
Axial Ratio & $A R(\theta, \phi) \geq 20 \mathrm{~dB}, \phi \in[-60,60](\mathrm{deg}) \cup \theta \in[75,105](\mathrm{deg})$ \\
Ellipticity Angle & $|\chi| \leq 10 \mathrm{deg}$ \\
\hline
\end{tabular}

The geometrical descriptors of the single radiator, $\Theta=\{a, b\} \cup\left\{\left(y_{k}, z_{k}\right), k=1, \ldots, K\right\}$ (Figure 2), have been determined by means of a customized PSO devoted to minimize a cost function quantifying the mismatch between requirements and performance of the synthesized arrangement of trial radiating elements. It is worth pointing out that the PSO has been chosen because of its well-known effectiveness and computational efficiency in dealing with nonlinear/non-differentiable cost functions and real-valued search-spaces [17-24], making it more suitable for the design problem at hand with respect to, for instance, genetic algorithms (GAs), which are more effective to deal with discrete/binary search spaces [17]. In order to match all conflicting requirements of Table 1 , the following cost function has been optimized through the PSO:

$$
\Phi(\Theta)=\sum_{q=1}^{Q} \alpha_{q} \Phi_{q}(\Theta),
$$

where $\alpha_{q}, q=1, \ldots, Q=5$, are real weights. In (1), $\Phi_{1}$ is the impedance matching term, defined as 


$$
\Phi_{1}(\Theta)=\int_{f_{\min }^{(p)}}^{f_{\max }^{(p)}}\left\{\frac{H\left[\left|S_{11}(f ; \Theta)\right|-S_{11}^{t h, p}\right]}{S_{11}^{t h, p}}\right\}^{2} d f+\sum_{v=1}^{2} \int_{f_{\min }^{\left(s_{v}\right)}}^{f_{\sin }^{\left(s_{v}\right)}}\left\{\frac{H\left[S_{11}^{t h, s_{v}}-\left|S_{11}(f ; \Theta)\right|\right]}{S_{11}^{t h, s_{v}}}\right\}^{2} d f
$$

where $\left|S_{11}(f ; \Theta)\right|$ is the magnitude of the reflection coefficient at frequency $f, S_{11}^{t h, p}$ and $S_{11}^{t h, s_{v}}$, $v=\{1 ; 2\}$, are the desired thresholds in both pass- and stop-bands (i.e, $S_{11}^{t h, p}=-10 \mathrm{~dB}, S_{11}^{t h, s_{1}}=-2 \mathrm{~dB}$, and $S_{11}^{t h, s_{2}}=-5 \mathrm{~dB}$-Table 1), while $H[\omega]=\omega$ if $\omega>0, H[\omega]=0$, otherwise. Moreover, $\Phi_{2}$ is the gain term defined as follows:

$$
\Phi_{2}(\Theta)=\int_{f_{\min }^{(p)}}^{f_{\max }^{(p)}}\left\{\frac{H\left[G_{\max }^{t h}-G_{\max }(f ; \Theta)\right]}{G_{\max }^{t h}}\right\}^{2} d f+\left\{\frac{H\left[\zeta(\Theta)-\zeta^{t h}\right]}{\zeta^{t h}}\right\}^{2},
$$

where $G_{\max }^{\text {th }}$ and $\zeta^{\text {th }}$ are respectively the desired realized gain and gain ripple (i.e., $G_{\max }^{\text {th }}=18 \mathrm{~dB}$ and $\zeta^{\text {th }}=1 \mathrm{~dB}$-Table 1). Furthermore, $\Phi_{3}$ is the beamwidth term defined as

$$
\begin{gathered}
\Phi_{3}(\Theta)=\int_{f_{\min }^{(p)}}^{f_{\max }^{(p)}}\left\{\frac{H\left[\left.H P B W\right|_{\phi=0}[\operatorname{deg}](f ; \Theta)-H P B W_{t h}\right]}{H P B W_{t h}}\right\}^{2} d f+ \\
\int_{f_{\min }^{(p)}}^{f_{\max }^{(p)}}\left\{\frac{H\left[\left.H P B W\right|_{\theta=90[\operatorname{deg}]}(f ; \Theta)-H P B W_{t h}\right]}{H P B W_{t h}}\right\}^{2} d f
\end{gathered}
$$

(the threshold being set to $H P B W_{t h}=25 \mathrm{deg}$ on both planes-Table 1), while $\Phi_{4}$ is the polarization term

$$
\Phi_{4}(\Theta)=\int_{f_{\min }^{(p)}}^{f_{\max }^{(p)}}\left\{\frac{H\left[|\chi(f ; \Theta)|-\chi^{t h]}\right]}{\chi^{t h}}\right\}^{2} d f+\int_{f_{\min }^{(p)}}^{f_{\max }^{(p)}} \int_{\theta_{\min }}^{\theta_{\max }} \int_{\phi_{\min }}^{\phi_{\max }}\left\{\frac{H\left[A R^{t h}-A R(f, \theta, \phi ; \Theta)\right]}{A R^{t h}}\right\}^{2} d \phi d \theta d f
$$

where $\chi^{\text {th }}$ and $A R^{\text {th }}$ are, respectively, the thresholds on the ellipticity angle and the axial ratio (i.e., $\chi^{\text {th }}=10 \mathrm{deg}$ and $A R^{\text {th }}=20 \mathrm{~dB}$-Table 1 ), while $\left[\theta_{\min }, \theta_{\max }\right]=[75,105][\mathrm{deg}]$ and $\left[\phi_{\min }, \phi_{\max }\right]=$ $[-60,60]$ (Table 1). Finally, $\Phi_{5}$ is the isolation term defined as

$$
\Phi_{5}(\Theta)=\sum_{n=2}^{9} \int_{f_{\min }^{(p)}}^{f_{\max }^{(p)}}\left\{\frac{H\left[\left|S_{n 1}(f ; \Theta)\right|-S_{n 1}^{t h}\right]}{S_{n 1}^{t h}}\right\}^{2} d f
$$

where $\left|S_{n 1}(f ; \Theta)\right|$ is the magnitude of the transmission coefficient between the central radiator $(n=1)$ and the $n$-th element in the array (Figure 1), while $S_{n 1}^{\text {th }}$ is the desired inter-element isolation (i.e, $S_{n 1}^{\text {th }}=-18 \mathrm{~dB}$ for $n=2, \ldots, 9-$ Table 1 ). Table 2 reports the values of the descriptors of the single element, $\Theta^{o p t}$, as yielded at the convergence of the PSO-based optimization, considering a setting of all weight terms in (1) to $\alpha_{q}=1, q=1, \ldots, Q$.

Table 2. HDI-based patch radiator $\left(\left[f_{\min }^{(p)}, f_{\max }^{(p)}\right]=[27.8,29.0](\mathrm{GHz}),\left[f_{\min }^{\left(s_{1}\right)}, f_{\max }^{\left(s_{1}\right)}\right]=[31.0,38.0]\right.$ $\left.(\mathrm{GHz}),\left[f_{\min }^{\left(s_{2}\right)} f_{\max }^{\left(s_{2}\right)}\right]=[50.0,55.0][\mathrm{GHz}]\right)-P S O-$ optimized descriptors, $\Theta^{\text {opt }}$.

\begin{tabular}{cccc}
\hline \multicolumn{4}{c}{ Geometrical Descriptors (mm) } \\
\hline$a$ & 0.10 & $z_{8}$ & 0.00 \\
$b$ & 1.89 & $y_{1}$ & 0.25 \\
$z_{1}$ & 0.00 & $y_{2}$ & 0.37 \\
$z_{2}$ & 1.38 & $y_{3}$ & 0.44 \\
$z_{3}$ & 1.04 & $y_{4}$ & 0.52 \\
$z_{4}$ & 1.36 & $y_{5}$ & 0.8 \\
$z_{5}$ & 1.00 & $y_{6}$ & 1.17 \\
$z_{6}$ & 0.45 & $y_{7}$ & 1.46 \\
$z_{7}$ & 0.61 & $y_{8}$ & 2.12 \\
\hline
\end{tabular}




\section{Full-Wave Validation}

This section is aimed at illustrating the radiation/electrical features of the synthesized elementary radiator (Table 2) analyzed through full-wave time-domain simulations based on the finite integration technique (FIT). Unlike a quite common standard in the literature, the effectiveness of the designed layout is evaluated with the radiating element integrated within the array arrangement and not stand-alone. In more detail, Section 3.1 deals with the performance metrics of the single array element when embedded in the center of the aperture (i.e., the radiation features of the element $n=1$ in Figure 1a have been analyzed while feeding such an element with unitary excitation and connecting all remaining elements $(n=2, \ldots, 25)$ to matched loads). Later on, the radiation behaviour of the planar arrangement of the synthesized spline-shaped radiators is shown (Section 3.2) to confirm the compliance of the final layout with the application-driven performance requirements (Table 1).

\subsection{Single Embedded Element Assessment}

In order to prove that the synthesized antenna properly radiates in the selected pass-band, while it enables suitable out-of-band filtering performance, Figure 3 shows the magnitude of the reflection coefficient, $\left|S_{11}(f)\right|$, measured at the input port of the central embedded element matched to a reference input impedance of $50 \Omega$ (i.e., $n=1$-Figure 1a) when connecting all $(N-1)$ neighbors to matched loads.

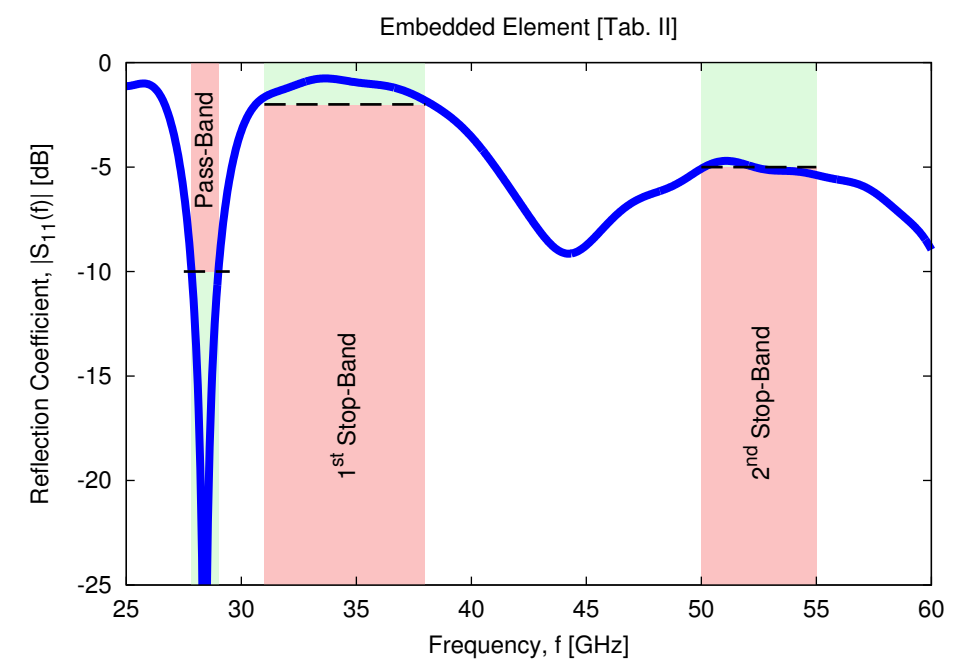

Figure 3. Single embedded element assessment $\left(\left[f_{\min }^{(p)}, f_{\max }^{(p)}\right]=[27.8,29.0](\mathrm{GHz}),\left[f_{\min }^{\left(s_{1}\right)}, f_{\max }^{\left(s_{1}\right)}\right]=\right.$ $\left.[31.0,38.0](\mathrm{GHz}),\left[f_{\min }^{\left(s_{2}\right)}, f_{\max }^{\left(s_{2}\right)}\right]=[50.0,55.0](\mathrm{GHz})\right)$-Magnitude of the input reflection coefficient, $\left|S_{11}(f)\right|$, versus the frequency, $f$.

As it can be inferred, there is a good impedance matching in the whole operational bandwidth since $\left|S_{11}(f)\right| \leq-10 \mathrm{~dB}, f \in\left[f_{\min ^{\prime}}^{(p)} f_{\max }^{(p)}\right]$. Moreover, the required signal rejection in the 1 st priority stop-band is properly yielded, being $\left|S_{11}(f)\right| \geq-2 \mathrm{~dB}, f \in\left[f_{\min }^{\left(s_{1}\right)}, f_{\max }^{\left(s_{1}\right)}\right]$ (Table 1 and Figure 3). As for the desirable interference cancellation in the 2nd priority stop-band, it turns out that the reflection coefficient is very close to the desired threshold (Table 1 ) and its value turns out to be always $\left|S_{11}(f)\right| \geq-5.5 \mathrm{~dB}, f \in\left[f_{\min }^{\left(s_{2}\right)}, f_{\max }^{\left(s_{2}\right)}\right]$ (Table 1 and Figure 3 ).

Moving from the electrical indexes to the radiation properties of the optimized radiator, the 3D realized gain patterns, $G(\theta, \phi)$, at the minimum $\left(f=f_{\min }^{(p)}\right.$-Figure $\left.4 a\right)$, central $\left(f=f_{c}^{(p)}\right.$-Figure $\left.4 \mathbf{b}\right)$, and maximum $\left(f=f_{\max }^{(p)}-\right.$ Figure $\left.4 c\right)$ working frequencies are reported in Figure 4. 


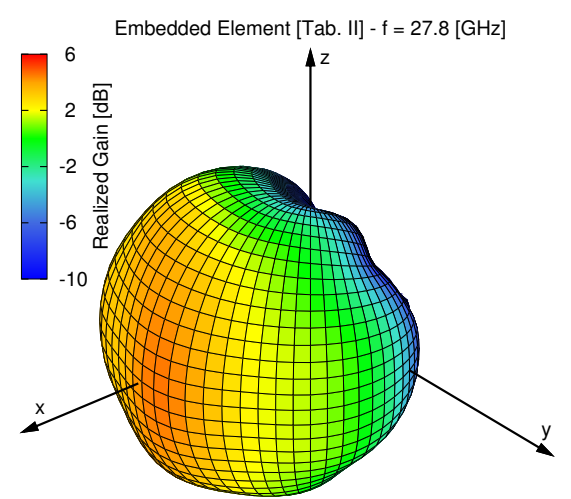

(a)

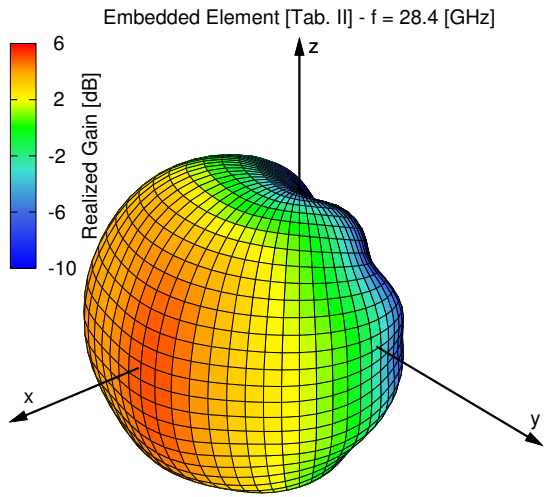

(b)

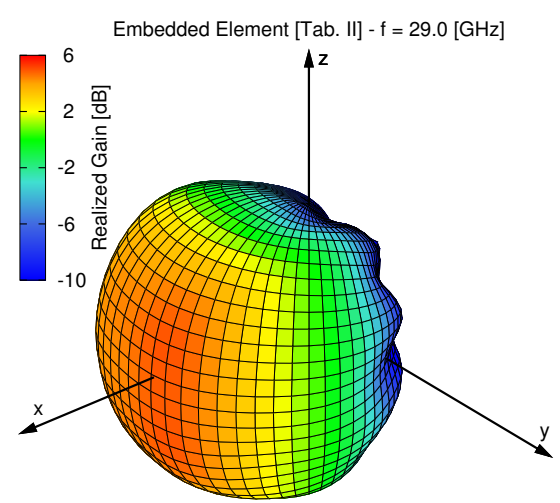

(c)

Figure 4. Single embedded element assessment $\left(\left[f_{\min }^{(p)}, f_{\max }^{(p)}\right]=[27.8,29.0](\mathrm{GHz})\right)-3 \mathrm{D}$ plot of the realized gain pattern at (a) $f=f_{\min }^{(p)} ;(\mathbf{b}) f=f_{c}^{(p)}$; and (c) $f_{\max }^{(p)}$.

These results show a high stability of the far-field patterns along the entire pass-band. Such outcomes are further verified by looking at the polar patterns reported in Figure 5 for the azimuthal (i.e., $\phi=0 \mathrm{deg}$-Figure 5a) and the elevation (i.e., $\theta=90 \mathrm{deg}$-Figure 5b) planes where the maximum realized gain is equal to $G_{\max }\left(f_{\min }^{(p)}\right)=4.61 \mathrm{~dB}$ (Figure $\left.4 \mathrm{a}\right), G_{\max }\left(f_{c}^{(p)}\right)=5.04 \mathrm{~dB}$ (Figure $4 \mathrm{~b}$ ), and $G_{\max }\left(f_{\max }^{(p)}\right)=5.04 \mathrm{~dB}$ (Figure $4 \mathrm{c}$ ).

Concerning the array scanning range, i.e., the angular region in which the element gain loss with respect to broadside is below $5 \mathrm{~dB}$ [25], the analysis of the beamwidth of the elementary radiator indicates that the scan cone of the array is fully supported both in azimuth $\left(\left.B W_{5[\mathrm{~dB}]}\right|_{\phi=0[\mathrm{deg}]} \geq\right.$ $120.3 \mathrm{deg}>\sigma$-Table 3$)$ and in elevation $\left(\left.B W_{5[\mathrm{~dB}]}\right|_{\theta=90[\mathrm{deg}]} \geq 120.9 \mathrm{deg}>\sigma\right.$-Table 3). Moreover, the $5 \mathrm{~dB}$ beamwidth turns out to be almost constant/stable versus the in-band frequency (i.e., $\left.B W_{5[\mathrm{~dB}]}\right|_{\phi=0[\mathrm{deg}]} \in[120.3,126.4](\mathrm{deg})$ and $\left.\left.B W_{5[\mathrm{~dB}]}\right|_{\theta=90[\mathrm{deg}]} \in[120.9,125.2](\mathrm{deg})\right)$.

Table 3. Single embedded element assessment $\left(\left[f_{\min }^{(p)}, f_{\max }^{(p)}\right]=[27.8,29.0](\mathrm{GHz}),\left[f_{\min }^{\left(s_{1}\right)} f_{\max }^{\left(s_{1}\right)}\right]=\right.$ $\left.[31.0,38.0](\mathrm{GHz}),\left[f_{\min }^{\left(s_{2}\right)}, f_{\max }^{\left(s_{2}\right)}\right]=[50.0,55.0](\mathrm{GHz})\right)$-Simulated $5 \mathrm{~dB}$ beamwidth, $B W_{5[\mathrm{~dB}]}$, values.

\begin{tabular}{ccc}
\hline$f(\mathrm{GHz})$ & $\left.\boldsymbol{B} \boldsymbol{W}_{\mathbf{5}[\mathrm{dB}]}\right|_{\boldsymbol{\phi}=\mathbf{0}[\mathrm{deg}]}(\mathbf{d e g})$ & $\left.\boldsymbol{B} \boldsymbol{W}_{\mathbf{5}[\mathrm{dB}]}\right|_{\boldsymbol{\theta}=\mathbf{9 0}[\mathrm{deg}]}(\mathbf{d e g})$ \\
\hline 27.8 & 126.4 & 125.2 \\
28.4 & 122.5 & 121.6 \\
29.0 & 120.3 & 120.9 \\
\hline
\end{tabular}




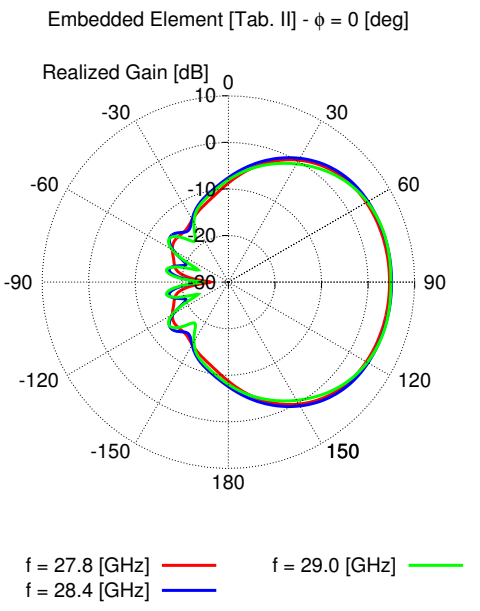

(a)

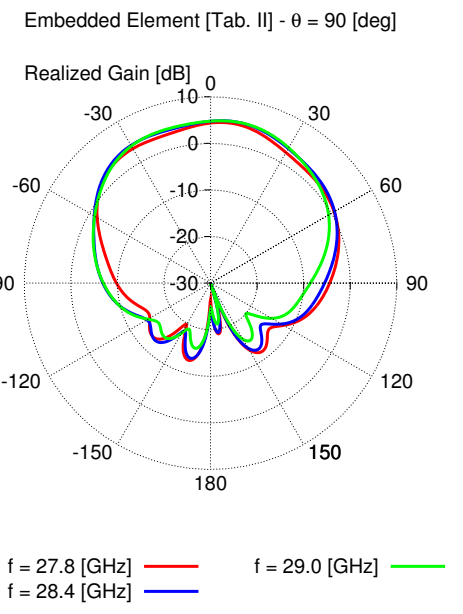

(b)

Figure 5. Single embedded element assessment $\left(\left[f_{\min }^{(p)} f_{\max }^{(p)}\right]=[27.8,29.0](\mathrm{GHz})\right)$-Polar plot realized gain pattern along the (a) azimuthal (i.e., $\phi=0 \mathrm{deg}$ ) and (b) the elevation (i.e., $\theta=90 \mathrm{deg}$ ) planes.

These outcomes confirm that the synthesized element will not introduce significant array gain distortions at the edge of the field-of-view within the entire pass-band.

In order to have some insights into the inter-element isolation, Figure 6 shows the magnitude of the scattering coefficients between the central embedded element and its closest neighbors (i.e., $\left|S_{n 1}(f)\right|, n=1, \ldots, 9$-Figure 1a). As it can be observed, the coupling between adjacent radiators is always very limited and it is compliant with the project threshold (Table 1) since $\left|S_{n 1}(f)\right|<-18.5 \mathrm{~dB}$, $f \in\left[f_{\min ^{\prime}}^{(p)} f_{\max }^{(p)}\right]$ (Figure 6).

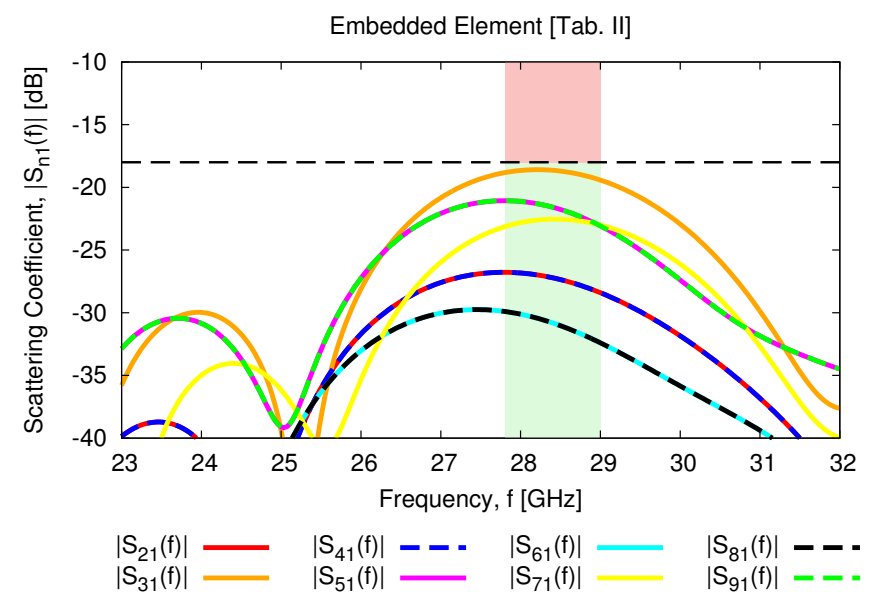

Figure 6. Single embedded element assessment $\left(\left[f_{\min }^{(p)} f_{\max }^{(p)}\right]=[27.8,29.0](\mathrm{GHz})\right)$-Magnitude of the inter-element scattering coefficients.

Finally, to better understand the basic operation of the synthesized antenna, Figure 7 shows the surface currents induced on the array patches at the central frequency of the pass-band $\left(f=f_{c}^{(p)}\right.$-Figure 7a) and of the first-priority $\left(f=f_{c}^{\left(s_{1}\right)} \triangleq \frac{f_{\min }^{\left(s_{1}\right)}+f_{\max }^{\left(s_{1}\right)}}{2}=34.5 \mathrm{GHz}\right.$-Figure 7b) and second-priority $\left(f=f_{c}^{\left(s_{2}\right)} \triangleq \frac{f_{\min }^{\left(s_{2}\right)}+f_{\max }^{\left(s_{2}\right)}}{2}=52.5 \mathrm{GHz}\right.$-Figure 7c) stop-bands. If, on the one hand, such results verify that the optimized spline shape properly resonates only within the required pass-band (the magnitude of the induced current on the active central element being significantly higher with respect to the out-of-band frequencies-Figure $7 \mathrm{a}$ vs. Figure $7 \mathrm{~b}, \mathrm{c}$ ); on the other hand, it should be 
remarked that the current induced through mutual coupling on adjacent radiators is quite limited (Figure 7a).

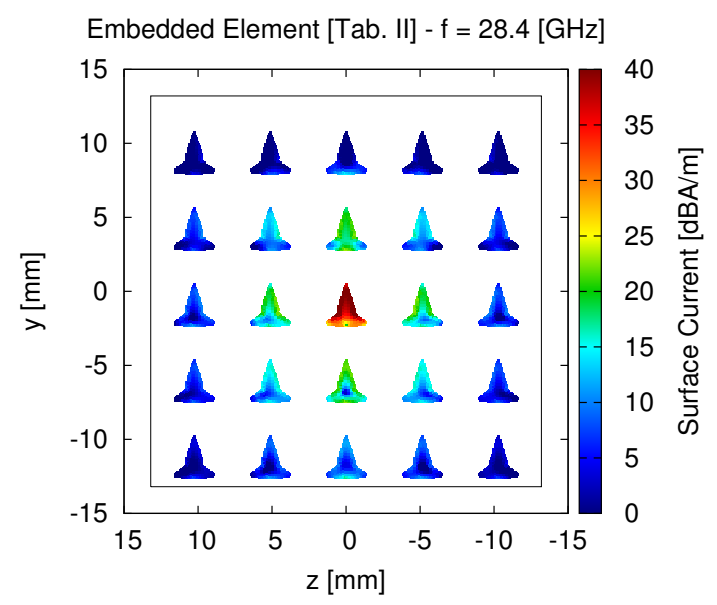

(a)

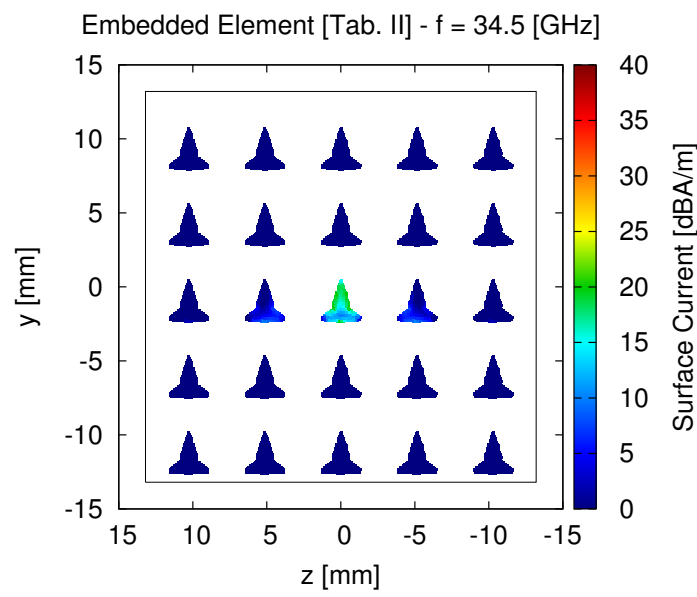

(b)

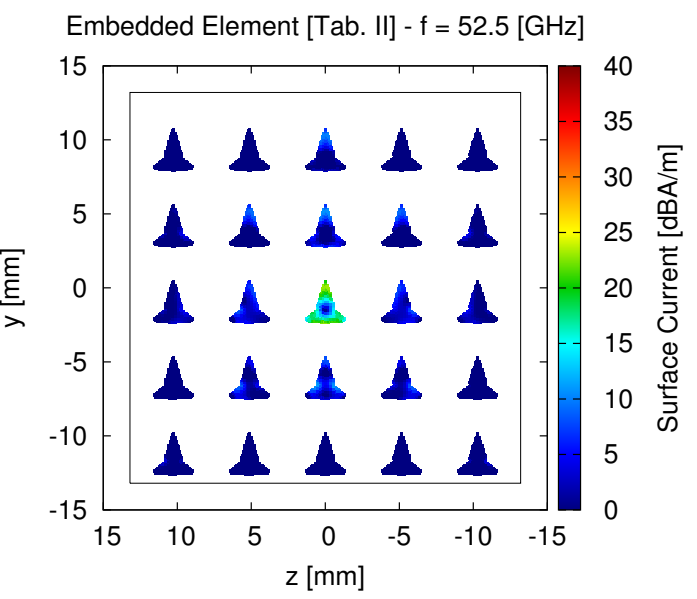

(c)

Figure 7. Single embedded element assessment $\left(\left[f_{\min }^{(p)}, f_{\max }^{(p)}\right]=[27.8,29.0](\mathrm{GHz}),\left[f_{\min }^{\left(s_{1}\right)}, f_{\max }^{\left(s_{1}\right)}\right]=\right.$ $[31.0,38.0](\mathrm{GHz}),\left[f_{\min }^{\left(s_{2}\right)}, f_{\max }^{\left(s_{2}\right)}\right]=[50.0,55.0](\mathrm{GHz})$-Surface current on the array patches when exciting the central embedded element $(n=1$-Figure 1$)$ at (a) $f=f_{c}^{(p)} ;(\mathbf{b}) f=f_{c}^{\left(s_{1}\right)}$; and (c) $f=f_{c}^{\left(s_{2}\right)}$.

\subsection{Planar Array Assessment}

Although the single-element checks in Section 3.1 are fundamental for the final design, the decisive analysis is on the radiation performance of the final planar uniformly-spaced arrangement of $N=25$ of those elementary radiators (Figure 1).

Towards this end, the 3D realized gain pattern of the fully excited array shown in Figure 8 has been computed at the minimum $\left(f=f_{\min }^{(p)}\right.$-Figure $\left.8 \mathbf{a}\right)$, the central $\left(f=f_{c}^{(p)}\right.$-Figure $\left.8 \mathbf{b}\right)$, and the maximum $\left(f=f_{\max }^{(p)}\right.$-Figure $8 \mathrm{c}$ ) operational frequencies. It turns out that the array behaves quite uniformly within the whole pass-band, with reduced back-radiations, and a single main beam properly directed towards broadside. By analyzing the corresponding polar plots in Figure 9 along the azimuthal (i.e., $\left.G(\theta, \phi)\right|_{\phi=0[\mathrm{deg}]}$-Figure 9a) and the elevation (i.e., $\left.G(\theta, \phi)\right|_{\theta=90[\mathrm{deg}]}$-Figure 9b) planes, one can notice that the sidelobe level (SLL) values are always low and suitable for a good suppression of potential interfering signals. In more detail, $\left.S L L\right|_{\phi=0[\mathrm{deg}]} ^{f_{\min }^{(p)}}=-13.1 \mathrm{~dB},\left.S L L\right|_{\phi=0[\mathrm{deg}]} ^{f_{c}^{(p)}}=-13.1 \mathrm{~dB}$, and $\left.S L L\right|_{\phi=0[\mathrm{deg}]} ^{f_{\max }^{(p)}}=-13.3 \mathrm{~dB}$ along the azimuth direction (Figure 9a) and, similarly, in elevation 
(i.e., $\left.S L L\right|_{\theta=90[\mathrm{deg}]} ^{f_{\mathrm{min}}^{(p)}}=-13.8 \mathrm{~dB},\left.S L L\right|_{\theta=90[\mathrm{deg}]} ^{f_{c}^{(p)}}=-13.5 \mathrm{~dB}$, and $\left.S L L\right|_{\theta=90[\mathrm{deg}]} ^{f_{\max }^{(p)}}=-13.3 \mathrm{~dB}$ ) (Figure $9 \mathrm{~b}$ ). It is worth remarking that the array requirement related to the radiation gain (Table 1 ) is fully satisfied as pointed out by the plot of the maximum realized gain versus the frequency in Figure 10. Indeed, $G_{\max }(f)$ is always greater than the desired threshold (i.e., $G_{\max }(f) \geq 18 \mathrm{~dB}, f \in\left[f_{\min ^{\prime}}^{(p)} f_{\max }^{(p)}\right]$-Table 1 ). There is an increase of about $13.64 \mathrm{~dB}$ with respect to the realized gain of the single-element at the central frequency (i.e., $18.68 \mathrm{~dB}$ vs. $5.04 \mathrm{~dB}$ ), which is in a good agreement with the rule-of-thumb experimentally assessed in [26] since an increment within $12 \mathrm{~d}$ and $15 \mathrm{~dB}$ is expected when displacing in an array configuration between $N=16$ and $N=32$ elements. As expected, such gain values are obtained only in the antenna pass-band with a maximum value of $\left.G_{\max }(f)\right|_{f=f_{\max }^{(p)}}=18.73 \mathrm{~dB}$ and an adequate ripple (i.e., $\zeta \leq 0.62 \mathrm{~dB}$-Figure 10 and Table 1). Otherwise, (i.e., $f \notin\left[f_{\min ^{\prime}}^{(p)} f_{\max }^{(p)}\right]$ ), there is a fast drop of $G_{\max }(f)$ (Figure 10).

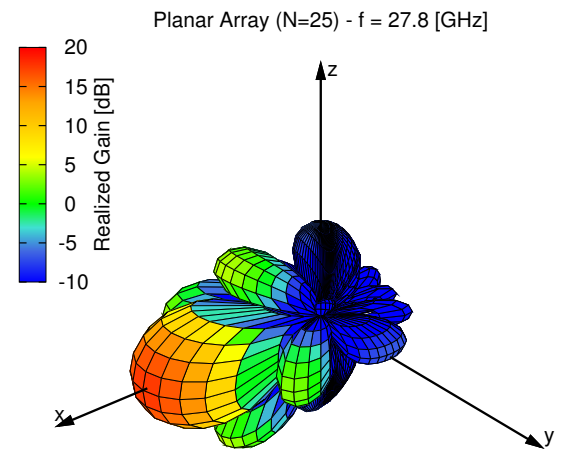

(a)

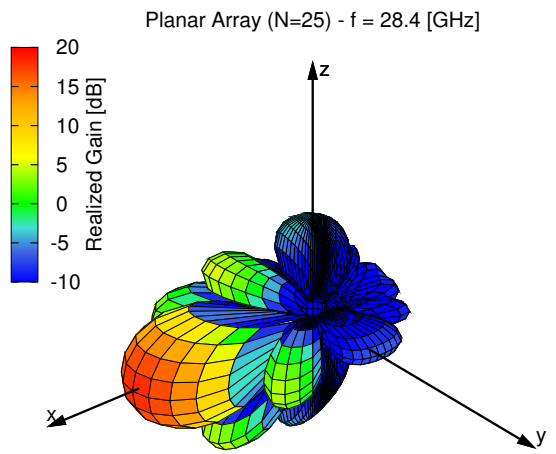

(b)

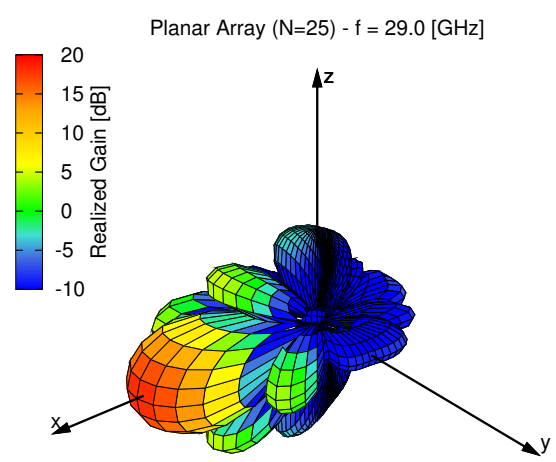

(c)

Figure 8. Planar array assessment $\left(N=25,\left[f_{\min ^{\prime}}^{(p)} f_{\max }^{(p)}\right]=[27.8,29.0](\mathrm{GHz})\right)-3 \mathrm{D}$ plot of realized gain pattern at (a) $f=f_{\min }^{(p)} ;(\mathbf{b}) f=f_{c}^{(p)}$; and (c) $f_{\max }^{(p)}$.

Dealing with the beam resolution of the array, the project requirements are also satisfied since the HPBW is always significantly below the desired threshold $H P B W_{t h}$ on both azimuthal (Figure $11 \mathrm{a}-\left.H P B W\right|_{\phi=0[\mathrm{deg}]} ^{f_{\min }^{(p)}}=21.6 \mathrm{deg},\left.H P B W\right|_{\phi=0[\mathrm{deg}]} ^{f_{c}^{(p)}}=20.7 \mathrm{deg}$, and $\left.H P B W\right|_{\phi=0[\mathrm{deg}]} ^{f_{\max }^{(p)}}=20.4 \mathrm{deg}$ ) and elevation (Figures $9 \mathrm{~b}$ and $11 \mathrm{~b}-\left.H P B W\right|_{\theta=90[\mathrm{deg}]} ^{f_{\text {min }}^{(p)}}=\left.21.0 \mathrm{deg} H P B W\right|_{\theta=90[\mathrm{deg}]} ^{f_{c}^{(p)}}=20.7 \mathrm{deg}$, and $\left.\left.H P B W\right|_{\theta=90[\mathrm{deg}]} ^{f_{\max }^{(p)}}=20.5 \mathrm{deg}\right)$ cuts.

Finally, let us analyze the polarization outcomes. The field radiated by the array is linearly (vertically) polarized with a high polarization purity as proved by the plot of the axial ratio in Figure 12 ( $\phi=0 \mathrm{deg}$-Figure 12a and and $\theta=90 \mathrm{deg}$-Figure 12b). Indeed, there is a good control of the cross-polarization over the angular region $\phi \in[-60,60]$ (deg) $\cup \theta \in[75,105]$ (deg), where $A R(f, \theta, \phi) \geq 20 \mathrm{~dB}$ according to the project guidelines (Table 1). Such an outcome on the polarization 
is further confirmed by the constant and almost ideal behavior of the ellipticity angle, $\chi(f)$, in Figure 13 (i.e., $\chi(f) \approx 0$ deg all along the pass-band).

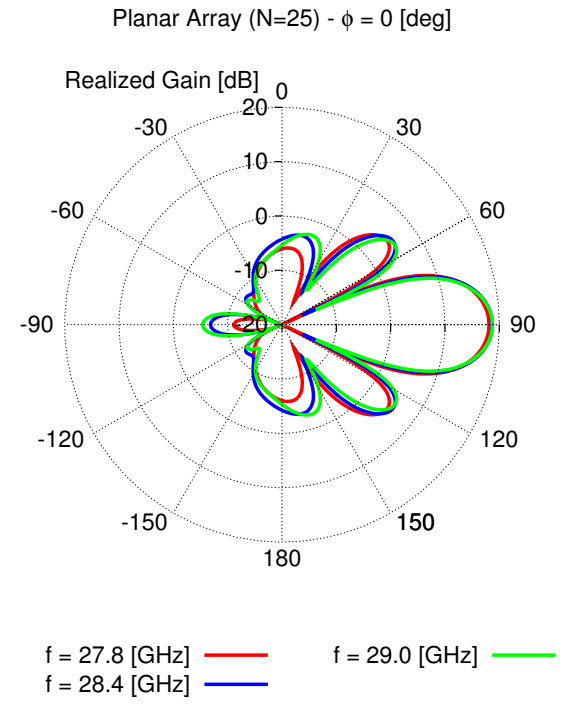

(a)

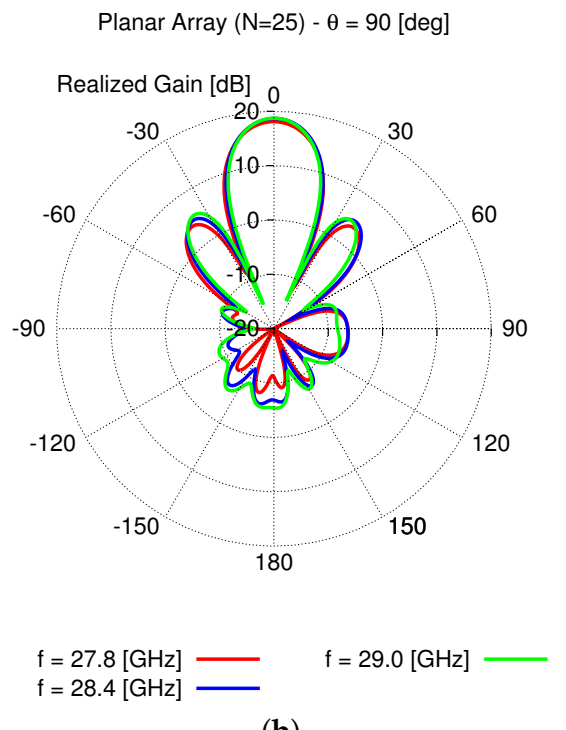

(b)

Figure 9. Planar array assessment $\left(N=25,\left[f_{\min ^{\prime}}^{(p)} f_{\max }^{(p)}\right]=[27.8,29.0](\mathrm{GHz})\right)$-Polar plot of the realized gain pattern along the (a) azimuthal (i.e., $\phi=0 \mathrm{deg}$ ) and (b) the elevation (i.e., $\theta=90 \mathrm{deg}$ ) planes.

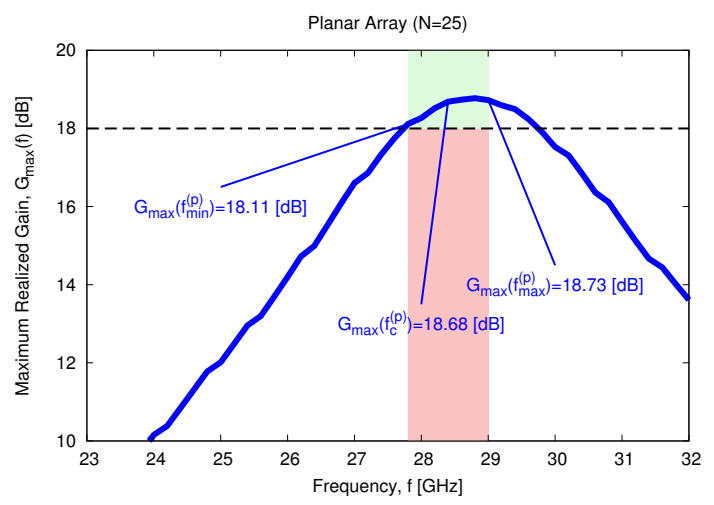

Figure 10. Planar array assessment $\left(N=25,\left[f_{\min ^{\prime}}^{(p)} f_{\max }^{(p)}\right]=[27.8,29.0](\mathrm{GHz})\right)$-Plot of the maximum realized gain, $G_{\max }(f)$, versus the frequency.

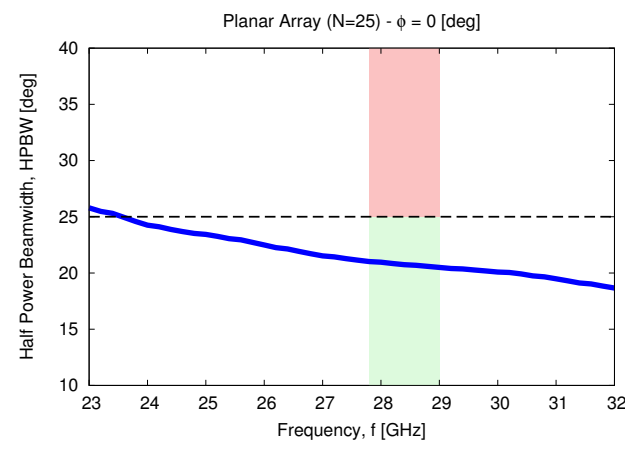

(a)

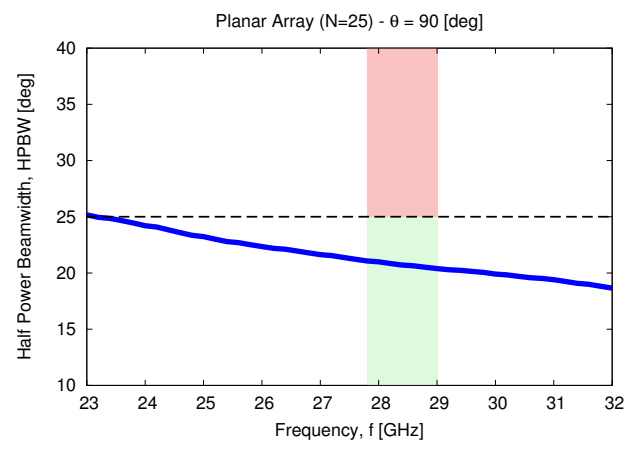

b

Figure 11. Planar array assessment $\left(N=25,\left[f_{\min ^{\prime}}^{(p)} f_{\max }^{(p)}\right]=[27.8,29.0][\mathrm{GHz}]\right)$-Plot of the HPBW versus the frequency along the (a) azimuthal (i.e., $\phi=0 \mathrm{deg}$ ) and (b) the elevation (i.e., $\theta=90 \mathrm{deg}$ ) planes. 


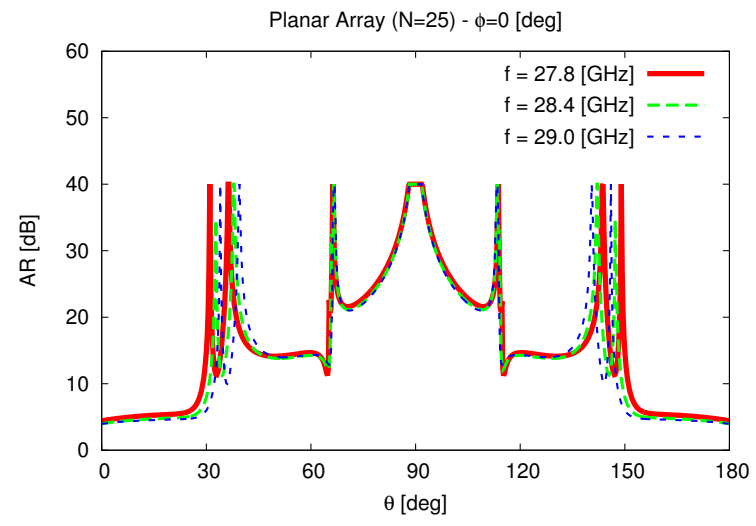

(a)

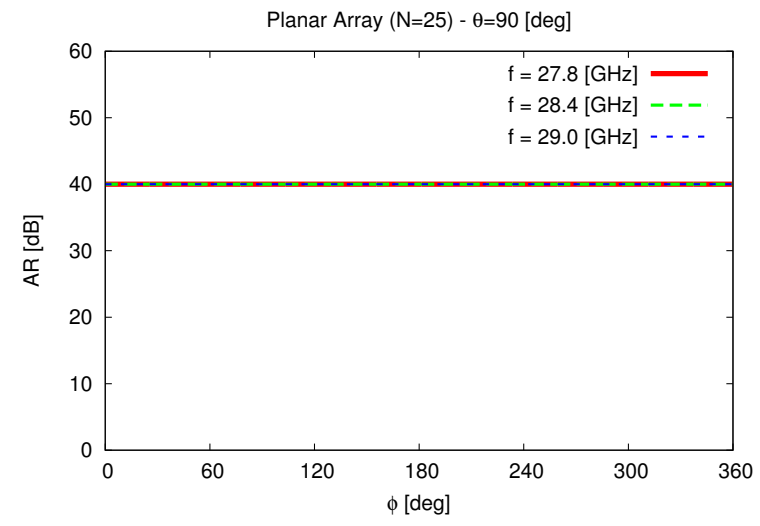

(b)

Figure 12. Planar array assessment $\left(N=25,\left[f_{\min ^{\prime}}^{(p)} f_{\max }^{(p)}\right]=[27.8,29.0](\mathrm{GHz})\right)$-Plot of the axial ratio, $A R(f, \theta, \phi)$, at $f=f_{\min ^{\prime}}^{(p)} f=f_{c}^{(p)}$, and $f=f_{\max }^{(p)}$ along the (a) azimuthal (i.e., $\phi=0$ deg and (b) the elevation (i.e., $\theta=90 \mathrm{deg}$ ) planes.

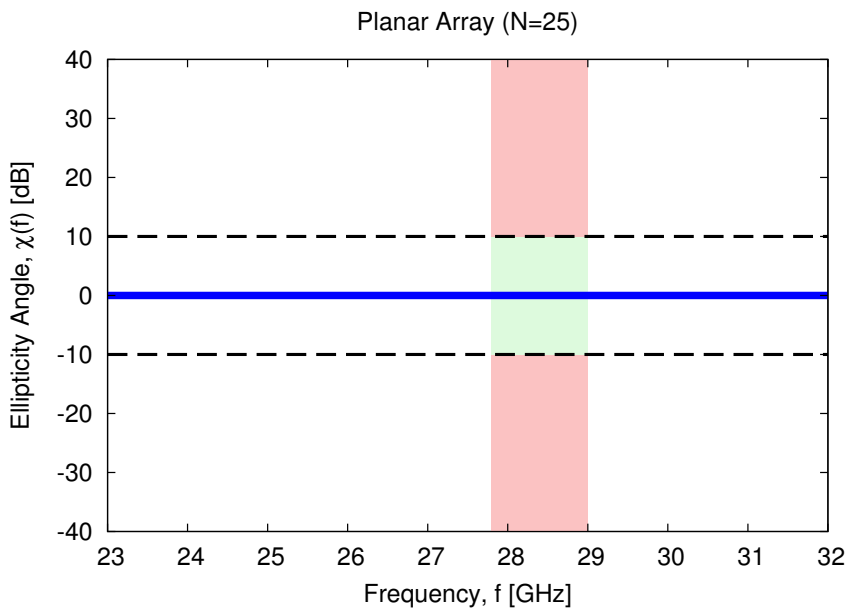

Figure 13. Planar array assessment $\left(N=25,\left[f_{\min ^{\prime}}^{(p)} f_{\max }^{(p)}\right]=[27.8,29.0](\mathrm{GHz})\right)$-Plot of the ellipticity angle, $\chi(f)$, versus the frequency.

\section{Conclusions}

A planar array for future $5 \mathrm{G} \mathrm{mm-wave} \mathrm{(28-GHz)} \mathrm{base} \mathrm{stations} \mathrm{has} \mathrm{been} \mathrm{proposed.} \mathrm{The} \mathrm{antenna}$ has been synthesized for HDI-based manufacturing technology with the objective of being compact/easy-to-integrate (the purpose of such a layered layout being the possibility to easily design buried routing and exploit high-density attributes) and having out-of-band filtering capabilities without using dedicated circuitry.

The layout of the single radiator has been determined by exploiting a spline-based shape modelling allowing to code, compared to other layouts, complex shapes through a limited number of DoFs (i.e., the spline control points) and enabling an easier fitting of the desired array performance [16] (Table 1), and a full-wave description of the interactions of the same element when embedded in the array. The results from an extensive analysis of both the embedded element and the full array (i.e., the arrangement of $N$ elementary radiators) have proved that the arising antenna exhibits suitable (i) in-band impedance matching, (ii) signal rejection within wide non-contiguous stop-bands, (iii) inter-element isolation, (iv) HPBW, and (v) polarization purity. Besides the exploitation of an HDI-oriented layout, the main novelties of the presented work with respect to published works are 
- the exploitation of a spline modeling of the patch contour to easily fit both required in-band matching and out-of-band rejection;

- the synthesis of the single radiator already embedded within the final array (rather than isolated in free-space), such that all mutual coupling effects are taken into account in the evaluation of the resulting array radiation features.

It should be noted that the design of the feeding network is out of the scope of the present work, and that the realization and later on the experimental assessment of a prototype are currently under investigation from an industrial partner for a future commercialization (besides the IPR issues and some contract constraints, please note that the realization of a provisional prototype is currently out-of-the-cost/technological possibilities of our university institution).

Author Contributions: The authors contributed equally to this work.

Acknowledgments: This work benefited from the networking activities carried out within the Cátedra de Excelencia UC3M-Santander funded by the Universidad Carlos III de Madrid (Spain) (A. Massa) and the Project "Antenne al Plasma-Tecnologia abilitante per SATCOM (ASI.EPT.COM)" funded by the Italian Space Agency (ASI) under Grant 2018-3-HH.0 (CUP: F91117000020005).

Conflicts of Interest: The authors declare no conflict of interest.

\section{References}

1. Muirhead, D.; Imran, M.A.; Arshad, K. A survey of the challenges, opportunities and use of multiple antennas in current and future 5G small cell base stations. IEEE Access 2016, 4, 2952-2964. [CrossRef]

2. Boccardi, F.; Heath, R.W.; Lozano, A.; Marzetta, T.L.; Popovski, P. Five disruptive technology directions for 5G. IEEE Commun. Mag. 2014, 52, 74-80. [CrossRef]

3. Hong, W.; Jiang, Z.H.; Yu, C.; Zhou, J.; Chen, P.; Yu, Z.; Zhang, H.; Yang, B.; Pang, X.; Jiang, M.; et al. Multi-beam antenna technologies for $5 \mathrm{G}$ wireless communications. IEEE Trans. Antennas Propag. 2017, 65, 6231-6249. [CrossRef]

4. Oliveri, G.; Gottardi, G.; Robol, F.; Polo, A.; Poli, L.; Salucci, M.; Chuan, M.; Massagrande, C.; Vinetti, P.; Mattivi, M.; et al. Co-design of unconventional array architectures and antenna elements for $5 \mathrm{G}$ base stations. IEEE Trans. Antennas Propag. 2017, 65, 6752-6767. [CrossRef]

5. Rocca, P.; Oliveri, G.; Mailloux, R.J.; Massa, A. Unconventional phased array architectures and design methodologies-A review. Proc. IEEE 2016, 104, 544-560. [CrossRef]

6. Ojaroudiparchin, N.; Shen, M.; Zhang, S.; Pedersen, G.F. A switchable 3-D-coverage-phased array antenna package for 5G mobile terminals. IEEE Antennas Wirel. Propag. Lett. 2016, 15, 1747-1750. [CrossRef]

7. Chu, H.; Guo, Y.X. A filtering dual-polarized antenna subarray targeting for base stations in millimeter-wave 5G wireless communications. IEEE Trans. Compon. Packag. Manuf. Technol. 2017, 7, 964-973. [CrossRef]

8. Park, S.J.; Shin, D.H.; Park, S.O. Low side-lobe substrate-integrated-waveguide antenna array using broadband unequal feeding network for millimeter-wave handset device. IEEE Trans. Antennas Propag. 2016, 64, 923-932. [CrossRef]

9. Khalily, M.; Tafazolli, R.; Rahman, T.A.; Kamarudin, M.R. Design of phased arrays of series-fed patch antennas with reduced number of the controllers for $28-\mathrm{GHz} \mathrm{mm}$-wave applications. IEEE Antennas Wirel. Propag. Lett. 2016, 15, 1305-1308. [CrossRef]

10. Dadgarpour, A.; Sharifi Sorkherizi, M.; Kishk, A.A. Wideband low-loss magnetoelectric dipole antenna for 5G wireless network with gain enhancement using meta lens and gap waveguide technology feeding. IEEE Trans. Antennas Propag. 2016, 64, 5094-5101. [CrossRef]

11. Hu, P.F.; Pan, Y.M.; Zhang, X.Y.; Zheng, S.Y. Broadband filtering dielectric resonator antenna with wide stopband. IEEE Trans. Antennas Propag. 2017, 65, 2079-2084. [CrossRef]

12. Zhang, X.Y.; Duan, W.; Pan, Y.M. High-gain filtering patch antenna without extra circuit. IEEE Trans. Antennas Propag. 2015, 63, 5883-5888. [CrossRef]

13. Cariou, M.; Potelon, B.; Quendo, C.; Cadiou, S.; Schlaffer, E.; Pessl, W.; Le Fevre, A. Compact X-band filter based on substrate integrated coaxial line stubs using advanced multilayer PCB technology. IEEE Trans. Microw. Theory Technol. 2017, 65, 496-503. [CrossRef] 
14. Chanchani, R.; Bethke, D.T.; Webb, D.B.; Sandoval, C.; Wouters, G.A. Development and RF characterization of high density integrated substrate technology. IEEE Trans. Compon. Packag. Technol. 2007, 30, 478-485. [CrossRef]

15. Holden, H. The HDI Handbook; BR Publishing Inc.: Seaside, OR, USA, 2009.

16. Lizzi, L.; Viani, F.; Azaro, R.; Massa. A. A PSO-driven spline-based shaping approach for ultra-wideband (UWB) antenna synthesis. IEEE Trans. Antennas Propag. 2008, 56, 2613-2621. [CrossRef]

17. Rocca, P.; Benedetti, M.; Donelli, M.; Franceschini, D.; Massa, A. Evolutionary optimization as applied to inverse problems. Inverse Probl. 2009, 25, 1-41. [CrossRef]

18. Robinson, J.; Rahmat-Samii, Y. Particle swarm optimization in electromagnetics. IEEE Trans. Antennas Propag. 2004, 52, 397-407. [CrossRef]

19. Viani, F.; Robol, F.; Salucci, M.; Azaro, R. Automatic EMI filter design through particle swarm optimization. IEEE Trans. Electromagn. Compat. 2017, 59, 1079-1094. [CrossRef]

20. Oliveri, G.; Viani, F.; Anselmi, N.; Massa, A. Synthesis of multi-layer WAIM coatings for planar phased arrays within the system-by-design framework. IEEE Trans. Antennas Propag. 2015, 63, 2482-2496. [CrossRef]

21. Bayraktar, Z.; Werner, D.H.; Werner, P.L. Miniature meander-line dipole antenna arrays designed via an orthogonal-array-initialized hybrid particle-swarm optimizer. IEEE Antennas Propag. Mag. 2011, 53, 42-59. [CrossRef]

22. Oliveri, G.; Salucci, M.; Anselmi, N.; Massa, A. Multiscale system-by-design synthesis of printed WAIMs for waveguide array enhancement. IEEE J. Multiscale Multiphys. Comp. Technol. 2017, 2, 84-96. [CrossRef]

23. Anselmi, N.; Rocca, P.; Salucci, M.; Massa, A. Optimization of excitation tolerances for robust beamforming in linear arrays. IET Microw. Antennas Propag. 2016, 10, 208-214. [CrossRef]

24. Viani, F.; Salucci, M.; Robol, F.; Massa, A. Multiband fractal Zigbee/WLAN antenna for ubiquitous wireless environments. J. Electromagn. Waves Appl. 2012, 26, 1554-1562. [CrossRef]

25. Hansen, R. Phased Array Antennas; John Wiley \& Sons: Hoboken, NJ, USA, 2009.

26. Jasik, H. Antenna Engineering Handbook, 1st ed.; McGraw-Hill: New York, NY, USA, 1961.

(C) 2018 by the authors. Licensee MDPI, Basel, Switzerland. This article is an open access article distributed under the terms and conditions of the Creative Commons Attribution (CC BY) license (http:/ / creativecommons.org/licenses/by/4.0/). 